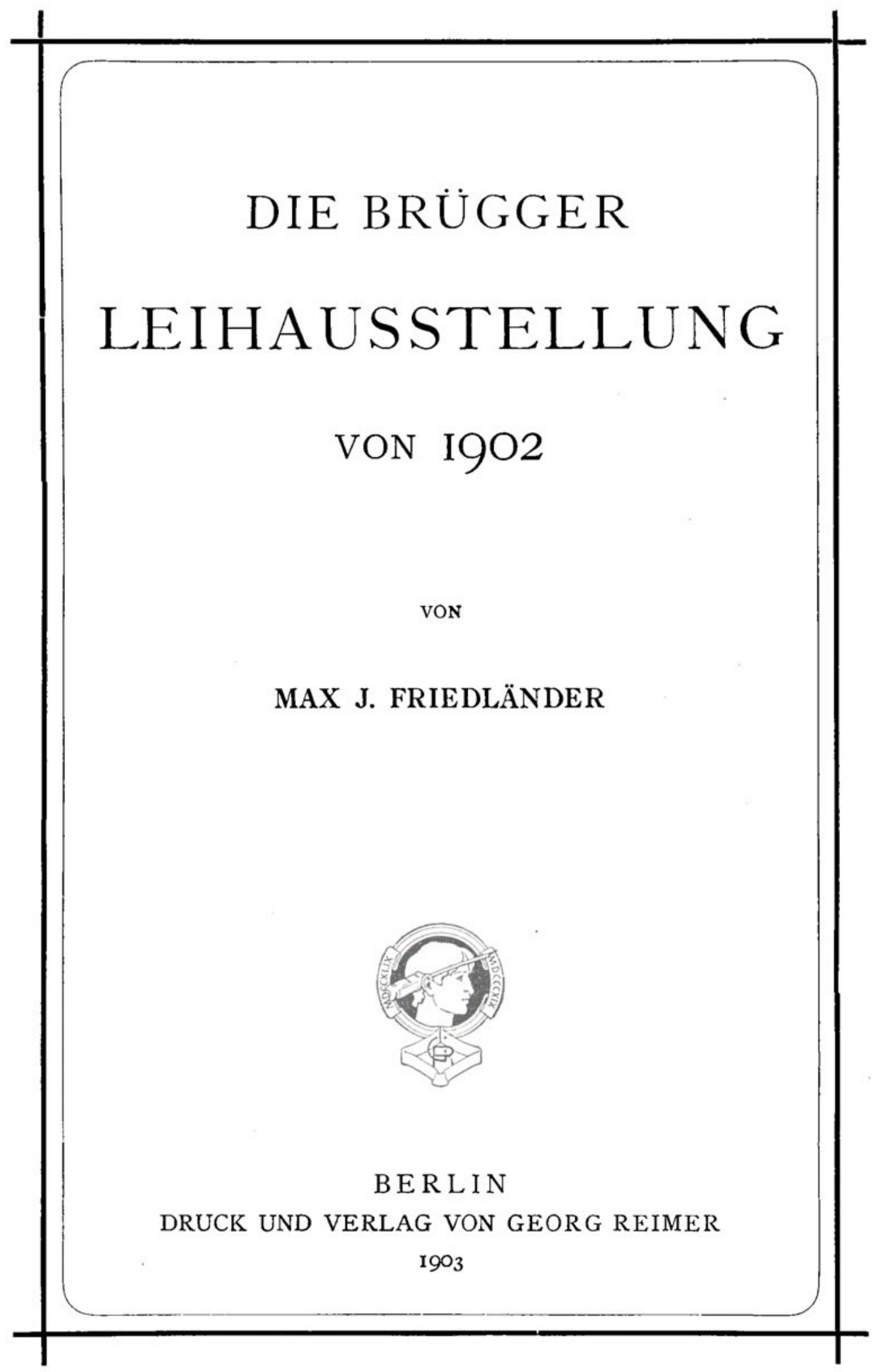


GEORG REIMER VERLAG
BERLIN W. 35 .

LUTZOWSTR, $107-8$.

\section{KOENIGLICHE MUSEEN ZU BERLIN}

Beschreibung der Bildwerke der christlichen Epochen

\section{— 2 weite Auflage $\equiv$ \\ DIE ELFENBEINBILDWERKE}

45 Lichtdrucktafeln in Mappe

Gross-Quart

nebst einem Textbande in octavo bearbeitet von W. VÖGE

Preis Mark 25.-

\section{DER \\ HILDESHEIMER SILBERFUND}

Herausgegeben und erläutert

von

ERICH PERNICE UND FRANZ WINTER

Royal. Mit 46 Lichtdrucktafeln und 43 Textabbildungen

Preis gebunden Mark 50.-

\section{ITALIENISCHE BILDHAUER DER RENAISSANCE}

Studien zur Geschichte der italienischen Plastik und Malerei auf Grund der Bildwerke und Gemälde in den Königl. Museen zu Berlin

von

WILHELM BODE

Oktav. VIII und 300 Seiten mit 43 Abbildungen

Preis geheftet Mark 10.50 


\section{DIE BRÜGGER \\ LEIHAUSSTELLUNG

\author{
VON I9O2
}

VON

\section{MAX J. FRIEDLÄNDER}

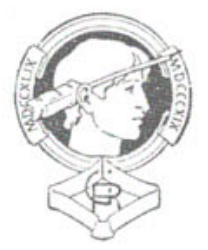

B E R L I N

DRUCK UND VERLAG VON GEORG REIMER 1903 
Diese Besprechung aller Tafelbilder, die 1902 zu Brugge ausgestellt waren, ist im XXVI. Bande des Repertoriums fur Kunstwissenschaft - 1903, S. $66 \mathrm{fr}$. und S. $147 \mathrm{ff}$. - erschienen. Hier ist ein Index hinzugefugt. 